\title{
Ayak Bileği Laterali Defektlerinin Distal Bazlı Peroneus Brevis Kas Flebi ile Onarılması
}

\section{Physical Inactivity Effects on Quality of Life in the Elderly}

\author{
Burak Özkan ${ }^{1 *}$, Abbas Albayati $^{1}$, Çağrı A. Uysal ${ }^{1}$, Nilgün M. Ertaş ${ }^{1}$ \\ ${ }^{1}$ Başkent Üniversitesi Tıp Fakültesi Plastik, Rekonstrüktif ve Estetik Cerrahi Anabilim Dalı, Ankara, Türkiye \\ e-mail: drburakozkan@gmail.com, albyati17@gmail.com, cagriuysal@hotmail.com,nilmarkal@yahoo.com.tr \\ ORCID: 0000-0003-3093-8369 \\ ORCID: 0000-0003-2806-3006 \\ ORCID: 0000-0001-6236-0050 \\ ORCID: 0000-0002-6944-1512 \\ *Sorumlu yazar/ Corresponding Author: Burak Özkan
}

Gönderim Tarihi / Received: 20.08.2020

Kabul Tarihi / Accepted: 24.09.2020

DOI: $10.34087 /$ cbusbed. 783236

Giriş ve Amaç: Ayak bileği laterali defektlerinin onarımında lokal doku seçenekleri oldukça kısıtlıdır. Distal bazlı peroneus brevis kas flebi lateral malleol bölgesinin onarımında kullanılan nadir lokorejyonel seçeneklerden biridir. $\mathrm{Bu}$ araştırma makalesinde, yüksek riskli hasta grubunda distal akımlı peroneus brevis kas flebiyle onarım tecrübelerimiz aktarılmıştır.

Gereç ve Yöntemler: 2018 ve 2020 yılları arasında Başkent Üniversitesi Plastik, Rekonstrüktif ve Estetik Cerrahi Anabilim Dalı'nda, lateral malleolar bölgedeki defetleri distal bazlı peroneus brevis kas flebi ile rekonstrükte edilmiș hastalar retrospektif olarak tarandı ve 5 hasta çalışmaya dahil edildi.

Bulgular: Hastaların ortalama yaşı 65.8 (50-77) idi. Defektlerin ortalama boyutu $19.6 \mathrm{~cm}^{2}$ idi. Fleplerde kayıp yaşanmadı. 2 hastada kas üzerine konulan deri greftinde kısmi kayıp görüldü , ek cerrahi müdahale olmadan konvansiyonel pansumanla sekonder iyileşme sağlandı. Ortalama 1.5 senelik takip döneminde onarım yapılan alanlarda yara ayrılması, akıntı, nüks görülmedi.

Sonuç: Distal bazlı peroneus brevis kas flebi, lateral malleolar bölge defektlerinin kapatılması için yüksek komorbidetesi olan hasta gruplarında bile güvenle kullanılacak bir lokorejyonel fleptir.

Anahtar kelimeler: Alt ekstremite rekonstrüksiyonu, Distal bazlı peroneus brevis kas flebi, Kronik yara, Peroneus brevis kas flebi.

\footnotetext{
Abstract

Objective:Local tissue options are limited in reconstruction of lateral ankle defects. Distally-based peroneus brevis muscle flap is one of the rare locoregional options used in reconstruction of lateral malleolar defects. In this research article, our experiences with distally based peroneus brevis muscle flap in high-risk patients were presented.

Materials and Methods: Patients whose defects were reconstructed with a distally-based peroneus brevis muscle flap in the lateral malleolar region between 2018 and 2020 were retrospectively screened and 5 patients were included in the study.

Results:The mean age of the patients was 65.8 (50-77). The average size of the defects was $19.6 \mathrm{~cm}^{2}$. No total flap loss were observed in the patients. Partial skin graft loss was observed in in 2 patients that secondary recovery was achieved with conventional wound dressing without additional surgical intervention. No wound dehiscence, discharge or recurrence was observed in the areas where repair was performed during an average of 1.5 years of follow-up. Conclusion: Distally-based peroneus brevis muscle flap is a locoregional flap to cover lateral malleolar region defects that can be used safely in patients with high comorbidities.
}

Keywords: Chronic wound, Distal base peroneus brevis muscle flap, Lower limb reconstruction, Peroneus brevis muscle flap. 


\section{Giriş}

Distal tibia bölgesindeki defektlerin kapatılması, rekonstrüktif cerrahlar için hep zorlayıcı olmuştur. Bu zorluğun sebebi; bölgede cilt altı yumuşak dokunun yetersizliği, tibia ve lateral malleoler kemiğin ince bir cilt tabakasının altında yer almasıdır. Bu anatomik özellikten dolay1, bölgenin geçireceği doku bütünlüğünü bozan travmalardan veya cerrahilerden sonra kemikler, yerleştirilen implantlar kolayca yüzeye çıkabilmektedir. Yetersiz cilt ve yumuşak doku nedeniyle bu yaraların kapatılması için bölgeye genellikle serbest flep cerrahisi gerekmektedir. Her ne kadar rekonstrüktif mikrocerrahideki gelişmelerle serbest flep kayıp oranları azalmış olsa da; uzun süreli ameliyatları rahatça tolere edemeyecek veya alıcı damar sorunu yaşanabilecek hastalarda bu bölgede lokal dokularla çözümlere ihtiyaç duyulmaktadır. Peroneus brevis kas flebi lateral malleolar bölgenin rekonstrüksiyonu için tanımlanmış nadir sayıda lokorejyonel fleplerden biridir [1]. Distal bazlı kaldırıldığında lateral malleolar bölge, ayak bileği, aşil bölgesi rekonstrüksiyonunda orta boyuttaki defektlerin rekonstrükte edilmesini sağlayabilmektedir. Bu çalışmamızda yüksek komorbideteli hasta grubundaki lateral malleolar bölge defektlerinin kapatılmasında distal bazlı peroneus brevis kas flebi ile ilgili tecbrübelerimiz anlatılmıştır.

\section{Materyal ve Metot}

2018 ve 2020 yılları arasında Başkent Üniversitesi Plastik, Rekonstrüktif ve Estetik Cerrahi Anabilim Dalı'nda, lateral malleolar bölgedeki defetleri distal bazlı peroneus brevis kas flebi ile rekonstrükte edilmiş 5 hastanın dosyaları tarandı ve retrospektif çalışmaya dahil edildi. Çalışma Helsinki Deklarasyonu prensipleri gözetilerek yapıldı. Hastalar; yaşları, cinsiyetleri, yaralarının etiyolojisi, defektlerin lokalizasyonu ve boyutu, komorbiditeleri, yaşanan komplikasyonlar ve takip süreleri yönünden incelendi. Çalışmadaki tüm hastalar aynı cerrah tarafından aynı cerrahi teknikle opere edildiler.

\subsection{Cerrahi Yöntem}

Tüm hastalar ameliyat öncesinde lateral malleolar bölge

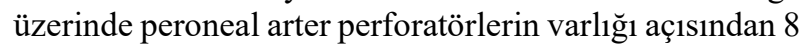
$\mathrm{Hz}$ el doppler ile incelendi ve perforatörler işaretlendi. Defekt ve lateral kompartman arasından herhangi bir cilt altı tünelizasyon, abse ve püy koleksiyonu olmadığına emin olundu. Ameliyat esnasında perforatör arterdeki nabzın ve kastaki kanamanın görülmesi açısından turnike kullanılmadi.

Hastalara sırt üstü yatarken uyluk 70 derece fleksiyonda, diz eklemi 90 derece fleksiyonda olacak şekilde ameliyat masasında pozisyon verildi. İlk olarak defektten başlanarak fibula başına uzanacak şekilde $\mathrm{S}$ şeklinde kesi yapıld1 cilt cilt dokular kat edilerek lateral kompartman insize edildi. İlk önce yüzeyelde yerleşimli peroneus longus kası ardında inferiorunda yerleşen peroneus brevis kası ortaya koyuldu. Fibula başından gelerek peroneus brevis kasını çaprazlayarak superomedialinden distale uzanan superfisial peroneal sinirin korunmasına özen gösterildi. Fibula kemiğine yapışık olan peroneus brevis kası, düşük enerjili elektro koter veya bistüri yardımiyla fibula periostundan proksimalden distale doğru ayrıldı. Kas, lateral malleolün $5 \mathrm{~cm}$ superioruna kadar segmental dalları klipslenerek hızlıca kaldırıldıktan sonra defter yaprağı gibi kendi üzerine katlanarak yetiştiği nokta tespit edildi. Defekte yetişmiyorsa işaretlenmiş en distal perforatöre kadar perforatör arterler klipslenerek flebin kaldırılma işlemine devam edildi. Kasın defekti örttüğü noktada diseksiyon bitirildi ve kasın dolaşımının intakt olduğundan emin olundu. Kasın defekte tespiti 2.0 Ethibon veya Vicryl dikiş materyaliyle yarı gömülü matris tekniğiyle tespit edildi. Verici saha primer kapatıldı. Primer kapanış sırasında cildin kasın katlandığı noktaya baskı yapmamasına özen gösterildi. Kas üzerine kısmi kalınlıkta deri grefti konulup, kas altı penröz drenler yerleştirilerek ameliyat sonlandırıldı.

\section{Bulgular ve Tartışma}

Hastaların ortalama yaşı 65.8 (50-77) idi. Hastaların tümü erkekti. Defektlerin ortalama boyutu $19.6 \mathrm{~cm} 2$ idi. Tüm hastaların yaraları lateral malleol veya ek olarak ayak bileği uzanımlıydı. Yara etiyolojileri 3 hastada kronik ülser, 1 hastada yanık , 1 hastada donuk şeklindeydi. 1 hastada eşlik eden lateral malleolar osteomyelit mevcuttu. 4 hastada diyabet, 1 hastada kronik böbrek yetmezliği vardı. Fleplerde kayıp yaşanmadı, 2 hastada kas üzerine konulan deri greftinde kısmi kayıp görüldü , ek cerrahi müdahale olmadan pansumanla sekonder iyileşme sağlandı. Ortalama 1.5 senelik takip döneminde onarım yapılan alanlarda yara ayrılması, akıntı, nüks görülmedi. Hastaların demografik ve klinik verileri Tablo 1' de gösterilmiştir.

\subsection{Vaka Örnekleri}

\subsubsection{Vaka 1}

77 yaşında erkek hasta tarafımıza sağ lateral malleolar açık yara nedeniyle ortopedi bölümü tarafından konsülte edildi (Resim 1). Hastanın hikayesinden, sağ lateral malleolar bölgede ülserle başlayan yaranın septik artrite neden olduğu öğrenildi. Bu problemine yönelik hasta iki kez eklem irrigasyonu ve kemik debridmanı için opere edilmişti. Özgeçmişinde 30 yıldır diyabetes mellitus ve diyabete sekonder gelişmiş kronik böbrek yetmezliği olan hastanın üç günde bir girmekte olduğu hemodiyaliz vardi. Hasta pre operatif olarak el doppleri ile lateral malleoler bölgesi dinlenerek peroneal arter dolaşımından emin olundu ve perforatörler işaretlendi. Intraoperatif olarak debridmanı takiben gelişen nihai defekt distal bazlı kaldırılan peroneus kas flebiyle rekonstrükte edidi (Resim 2) . Kas üzerine kısmi kalınlıkta deri grefti serildi. Hastada erken ve geç dönemde komplikasyon görülmedi (Resim 3). 
Tablo 1. Distal bazlı peroneus brevis kas flebiyle rekonstrükte edilen hastaların demografik ve klinik dağılımı

\begin{tabular}{|c|c|c|c|c|c|c|c|}
\hline Hasta & $\begin{array}{l}\text { Cinsiye } \\
\text { t }\end{array}$ & Yaş & $\begin{array}{l}\text { Hastanın } \\
\text { komorbiditeleri }\end{array}$ & $\begin{array}{l}\text { Defektin } \\
\text { Lokalizasyonu }\end{array}$ & Etiyolojisi & Boyutu & Komplikasyon \\
\hline Hasta 1 & Erkek & 77 & $\begin{array}{l}\text { Tip II diyabet } \\
\text { Kronik böbrek } \\
\text { yetmezliği } \\
\text { Periferik arter } \\
\text { Hastalığı }\end{array}$ & Lateral malleol & $\begin{array}{l}\text { Kronik } \\
\text { ülser } \\
\text { Osteomyeli } \\
\text { t }\end{array}$ & $2 \times 3 \mathrm{~cm}$ & - \\
\hline Hasta 2 & Erkek & 67 & $\begin{array}{l}\text { Tip II diyabet } \\
\text { Venöz yetmezlik } \\
\text { Periferik arter } \\
\text { hastalığ1 }\end{array}$ & Lateral malleol & $\begin{array}{l}\text { Kronik } \\
\text { venöz ülser }\end{array}$ & $7 \times 5 \mathrm{~cm}$ & $\begin{array}{l}\text { Kismi deri grefti } \\
\text { kaybi }\end{array}$ \\
\hline Hasta 3 & Erkek & 50 & Tip I diyabet & $\begin{array}{l}\text { Lateral malleol } \\
\text { ve tibia distali }\end{array}$ & Yanık & $3 \times 3 \mathrm{~cm}$ & - \\
\hline Hasta 4 & Erkek & 70 & $\begin{array}{l}\text { Tip II diyabet } \\
\text { Kronik böbrek } \\
\text { yetmezliği } \\
\text { Periferik arter } \\
\text { Hastalığı }\end{array}$ & $\begin{array}{l}\text { Lateral malleol } \\
\text {, ayak dorsumu }\end{array}$ & Donuk & $7 \times 4 \mathrm{~cm}$ & - \\
\hline Hasta 5 & Erkek & 65 & $\begin{array}{l}\text { Tip II diyabet } \\
\text { Venöz ülser }\end{array}$ & $\begin{array}{l}\text { Lateral malleol } \\
\text { ve aşil bölgesi }\end{array}$ & $\begin{array}{l}\text { Kronik } \\
\text { venöz ülser }\end{array}$ & $5 \times 4 \mathrm{~cm}$ & $\begin{array}{l}\text { Kısmi deri grefti } \\
\text { kayb1 }\end{array}$ \\
\hline
\end{tabular}

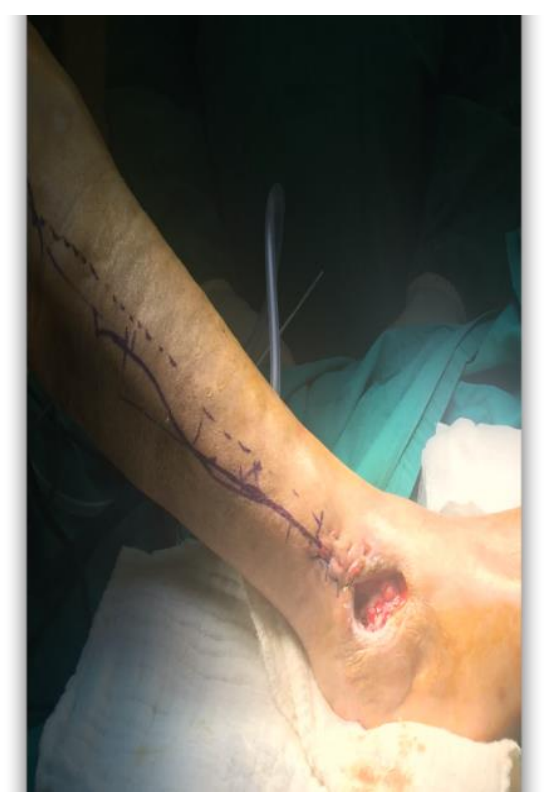

Resim 1. Lateral malleoler bölgede kronik ülser ve osteomyelit sonrası gelişen $2 \times 3$ cm lik tam kat defekt

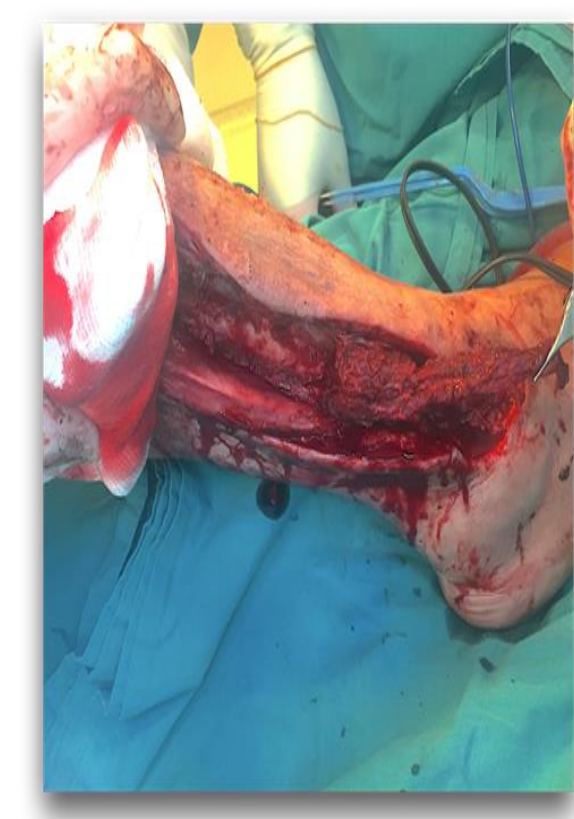

Resim 2.

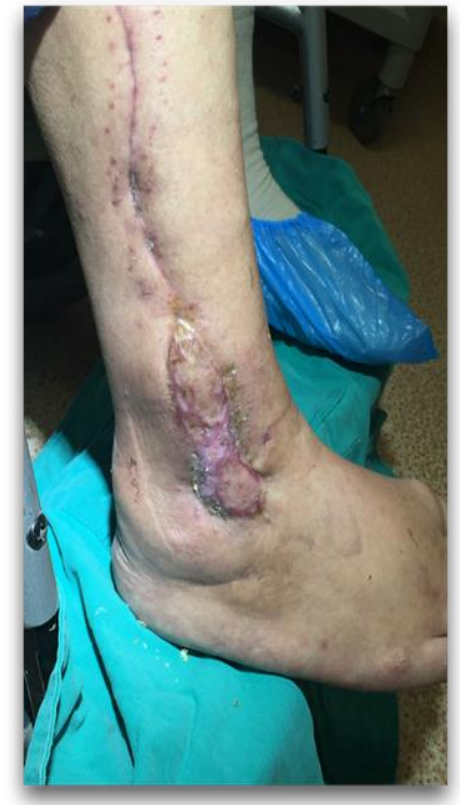

Resim 3. Hastanın ameliyat sonrası 3. aydaki görünümü 


\subsubsection{Vaka 2}

67 yaşındaki erkek hasta kliniğimize sol lateral malleolar bölgedeki 7x5 cm boyutlarındaki yara için başvurdu. Hikayesinde yarasının yaklaşık 6 aydır mevcut olduğu, yaranın pansuman ve hareket sırasında aşırı ağrılı olduğunu aktardı. Özgeçmişinde, 10 yıldır düzensiz seyreden kan şekerleriyle birlikte tip 2 diyabet ve 5 y1l mevcut alt ekstremitede venöz yetmezlik vard1. Ameliyat öncesi çekilen ayak bileği manyetik rezonans görüntülemeyle altta yatabilecek osteomyelit, cilt atlı tünelizasyon gibi problemler dışlandı. Yara yerinden alınan doku biyopsisi kültüründe üreme olmayan hastaya distal bazlı peroneus brevis kas flebi ile rekonstrüksiyon planland1. Pre operatif olarak el doppleri peroneal perforatörler işaretlendi. Intra operatif debridmanı takiben kas flebi kaldırıldı (Resim 4.)

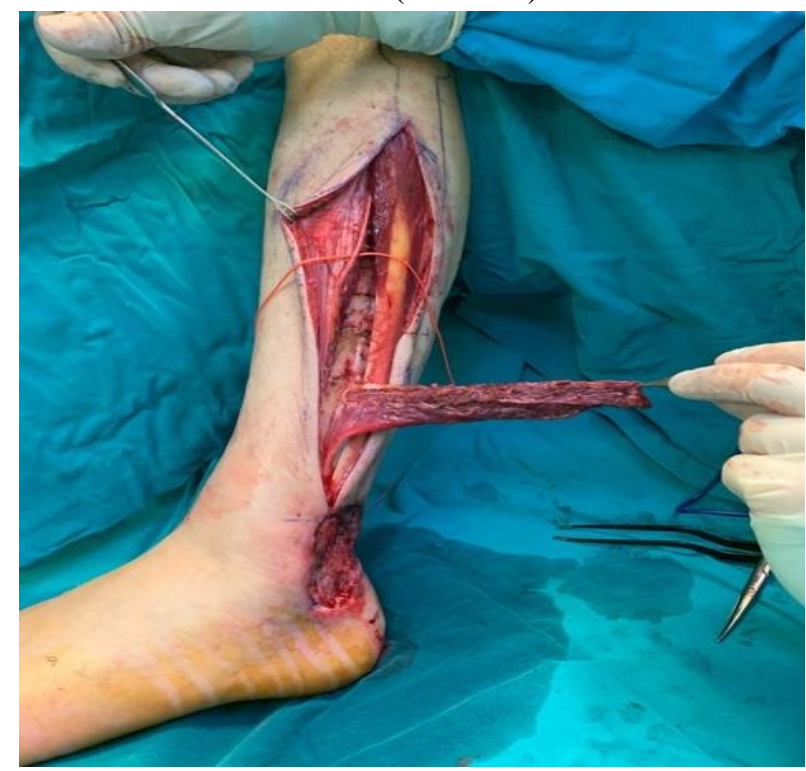

Resim 4. Peroneus brevis kasının distal bazlı olacak şekilde kaldırılması. Superiorda yüzeyel peronel sinir vessel loupe üzerinde görülmektedir.

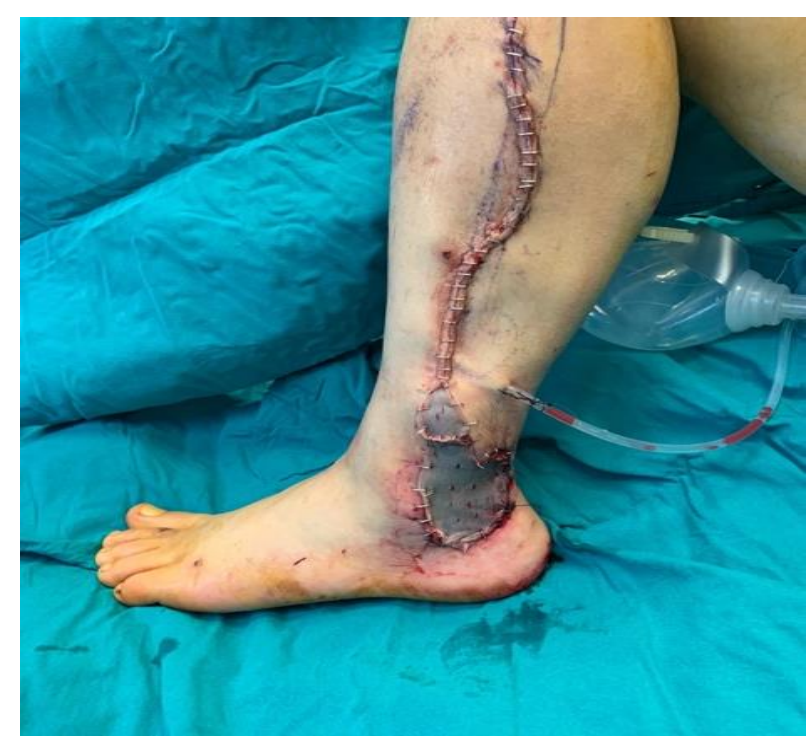

Resim 5. Peroneus brevis kasının üzerine kısmi kalınlıkta deri grefti koyulmas1.
Defektin ayak lateralinde distale doğru uzanması sebebiyle en distal perforatör korunacak şekilde peroneus brevis kası serbestlendi ve defekte adapte edildi. Kas üzerine kısmi kalınlıkta deri grefti konuldu (Resim 5). Post operatif 10 günde kas distalindeki $4 \times 4 \mathrm{~cm}$ lik alanda deri grefti kayb1 görüldü. Hasta konvansiyonel pansumanlarla takip edildi. Post operatif 4. ayda hastada tam iyileşme sağlandı (Resim 6).

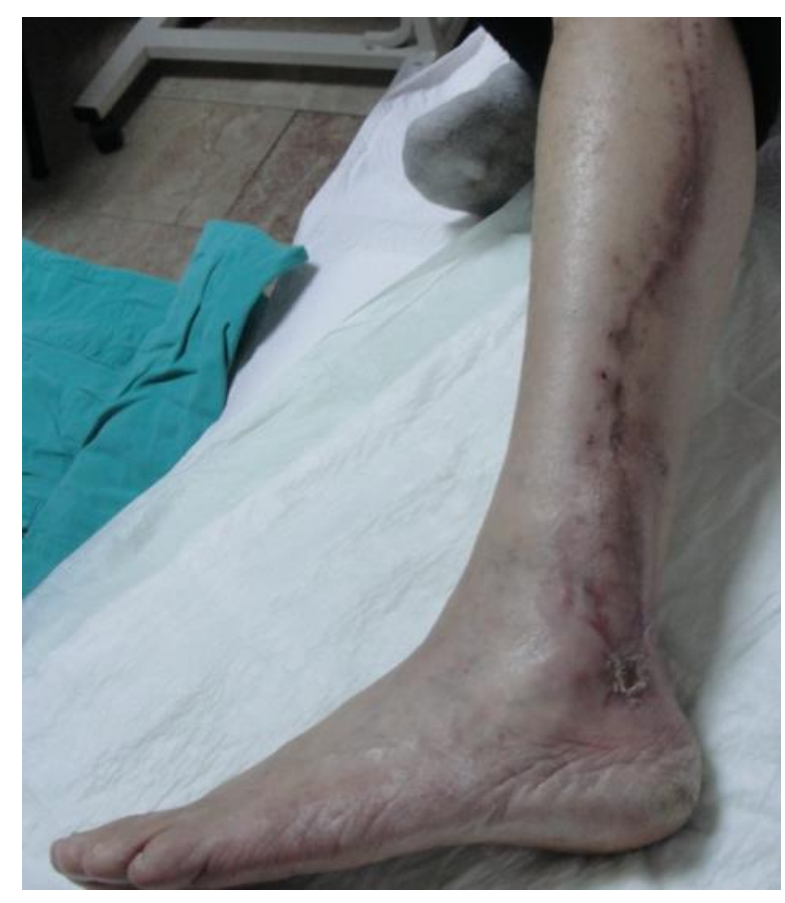

Resim 6. Ameliyat sonrası dördüncü ayda distalde greft nekrozu görülen alanın sekonder iyileşmesinin tamamlanmış hali görülmektedir.

Tibianın distalindeki defektlerde lokorejyonel rekonstrüksiyon seçenekleri kısıtlıdır. Ayak bileği bölgesinde tibial ve peroneal kaslar tendonlaşmaya başlayarak cilt incelir ve kemik yapılar yüzeyelleşmiştir. Bu anatomik özellikten dolayı bölgeye ters akımlı flepler veya distal bazlı kaldırılan kas flepleri haricinde konvansiyonel rekonstrüksiyon yöntemleri sınırlıdır.

Ters akımlı fleplerden en bilineni ters akımlı sural arter flebidir [2]. Peroneal arter ile sural arter arasındaki anostomozlardan beslenen bu flep, topuk, aşil bölgesi, medial ve lateral malleolar bölgedeki defektleri kapatabilmektedir. Ters akımlı olmasından dolayı cilt adasının yaşaya bilirliğinin arttırılması için özellikle cerrahi geciktirmenin yapılması flebin iki veya üç seansta nakledilmesi önerilmektedir [3,4]. Flebin yarattığ cerrahi skar fazladır ve venöz yetmezlik sorunları sıktır. Çok seanslı olması, hasta pozisyon verilmesi ile ilgili problemler bu flebin en önemli dezavantajıdır. Biz de bu olumsuzluklar nedeniyle ters akımlı sural arter flebini tercih etmektedik.

Ters akımlı kullanılabilecek başka bir flep posterior tibial arter flebidir [5]. Bacak medialinde yaratacağı geniş skar ve posterior tibial arterin sakrifiye edilmesi ve sinirin zedeleme ihtimali nedeniyle rekonstrüktif basamakta ön siralarda yer almamaktadir. 
Ayak bileği bölgesi defektlerinde diğer kullanılabilecek yöntemler serbest flepler ve perforatör propellar fleplerdir. Serbest flepler, iyi kanlanan güvenilir bir dokunun defekt alanındaki arter ve ven anostomozları vasitasiyla nakledilmesi ile defekt onarımı sağlamaktadırlar. Distal üçte bir tibia, ayak bileği geniş defektlerinde tedavide altın standarttır [6]. Fakat, serbest flep cerrahisi her hastaya uygulanamamaktadır. Hastada alıcı damarların sağlıklı olmasına ve uzun süreli bir ameliyatı tolere edebilecek kardiyovasküler rezerve ihtiyaç vardır [7]. Serimizdeki hastalarımızın 4'ünde ileri periferik arteryel hastalık ve 1 hastada eşlik eden venöz yetmezlik olması sebebiyle serbest flep cerrahisi tercih edilmemiştir. Perforatör propellar flepler ile ayak bileği bölgesinde başarılı seriler bildirilmiştir. 180 derecelik rotasyon arkına sahip olan bu flepler serbest flep alternatifidir. Bu fleplerin öğrenme eğrisi uzundur ve teknik ekipman gereksinimi vardır [8]. Propellar flepleri, yeterli hacim ve obliterasyon kapasitesine sahip olmamaları nedeniyle zeminde osteomyelit olan vakalarda tercih etmiyoruz.

Distal akımlı peroneus brevis flebinin anatomisi ile ilgili birçok çalışma yapılmıştır $[9,10]$. Peroneus brevis kası peroneal arter perforatörlerinden ve az oranda anterior tibial arterden beslenmektedir [11]. Peroneal arter, diyabetik makroanjiopati ve periferik damar hastalığında poplitea distalinde en az etkilenen arterdir [12,13]. Bu nedenle, distal akımlı peroneus brevis kas flebi diyabetik ve periferik arter hastalığı olan hasta grubunda güvenilir kabul edilebilir. Üç boyutlu manyetik rezonans görüntüleme ve ultrasonografik değerlendirme, flebin planlanması aşamasında kasın kondisyonu ile peroneal arterin intaklığını göstermesi açısından faydalı olabilir[14, 15]. Kasin innervasyonu superfisial peroneal sinir dalıyla sağlanır. Flep kaldırılırken bu dalın kesilmesi gerekmektedir. $\mathrm{Bu}$ esnada ana sinirin korunması önem arz etmektedir. Ensat ve arkadaşları lateral malleole en yakın perforatörlerin $4 \mathrm{~cm}$ olduğunu ve pivot noktanın lateral malleola $6 \mathrm{~cm}$ mesafeden kaldırılması gerektiğini belirtmişlerdir [11]. Schmidt ve arkadaşları fibular kemik segmenti de katarak ayak bileği ve topuk bölgesindeki kemik defektlerini rekonstrükte edebilmişlerdir [16]. Birçok seride lateral ayak bileği bölgesindeki orta ve küçük çaplı defektler zeminde yatan osteomyelit, protez ekspozisyonu gibi farklı endikasyonlarda bu fleple rekonstrükte edilebilmiştir. Bu flebin en çok bildirilen komplikasyonu kas üzerine serilen deri greftinin kaybıdır [17]. Bizim de serimizde literatürle uyumlu olarak iki hastada deri grefti kayb1 yaşanmıştır. Bu sorunun çözümü için ise flebin distal 2 cm'lik kısmının eksize edilmesi, negatif basınçlı yara tedavisi, geç greftleme veya konvansiyonel pansumanla takip, sekonder iyileşmenin beklenmesi önerilmiştir[16, 17, 18].

\section{Sonuc}

Distal akımlı peroneus brevis kas flebi, lokorejyonel rekonstrüksiyon seçeneklerin kısıtlı olduğu ayak bileği lateralinde küçük ve orta çaplı defektlerde komorbid hastalarda dahi güvenle kullanılabilecek bir fleptir.

\section{Referanslar}

1.Eren, S, Ghofrani, A, Reifenrath, M, The distally pedicled peroneus brevis muscle flap: A new flap for the lower leg, Plastic and Reconstructive Surgery, 2001, 107,1443-1448.

2. Jeng, S.F, Wei, F.C, Distally based sural island flap for foot and ankle reconstruction, Plastic and Reconstructive Surgery, 1997, 99(3), 744-750.

3. Tosun, Z, Ozkan, A, Karaçor, Z, Savaci, N, Delaying the reverse sural 6. flap provides predictable results for complicated wounds in diabetic foot, Annals of Plastic Surgery, 2005, 55, 169-73.

4. Karamese, M, Yıldıran, G.U, Akdağ, O, Selimoglu, N.M, Abacı, M, Tosun, Z, An Alternative to Free Flap for Ankle and Heel Defects: Delayed-Reverse Flow Sural Island Flap, Turkish of Plastic Surgery, 2015, 23(1), 27-32

5. Mardini, S, Salgado, C.J, Chen, H.C, Yazar, S, Ozkan, O, Sassu, P, Posterior tibial artery flap in poliomyelitis patients with lower extremity paralysis, Plastic and Reconstructive Surgery, 2006,117(2), 640-645

6.Cho, E.H, Shammas, R.L, Carney, M.J, et al, Muscle versus Fasciocutaneous Free Flaps in Lower Extremity Traumatic Reconstruction: A Multicenter Outcomes Analysis, Plastic and Reconstructive Surgery, 2018, 141(1), 191-199.

7.El-Sabbagh, A.H, Non-microsurgical skin flaps for reconstruction of difficult wounds in distal leg and foot, Chinese Journal of Traumatology, 2018, 21(4), 197-205.

8. Brunetti, B, Barone, M, Tenna, S, Salzillo, R, Segreto, F, Persichetti, $P$, Pedicled perforator-based flaps: Risk factor analysis, outcomes evaluation and decisional algorithm based on 130 consecutive reconstructions, Microsurgery, 2020, 40(5), 545-552.

9. Hughes, L.A, Mahoney, J.L, Anatomic basis of local muscle flaps in the distal third of the leg, Plastic and Reconstructive Surgery, 1993, 92(06), 1144-1154.

10. Lyle, W.G, Colborn, G.L, The peroneus brevis muscle flap for lower leg defects, Annals of Plastic Surgery, 2000, 44(02), 158-162.

11. Ensat, F, Weitgasser, L, Hladik, M, et al, Redefining the vascular anatomy of the peroneus brevis muscle flap, Microsurgery, 2015, 35, 39-44.

12. Chen, Y.L, Zheng, B.G, Zhu, J.M, et al, Microsurgical anatomy of the lateral skin flap of the leg, Annals of Plastic Surgery, 1985, $15,313-318$.

13. Graziani, L, Silvestro, A, Bertone, V, et al, Vascular involvement in diabetic subjects with ischemic foot ulcer: a new morphologic categorization of disease severity, European Journal of Vascular and Endovascular Surgery, 2007, 33(4), 453-460.

14. Barbera, F, Lorenzetti, F, Marsili, R, et al, MRI anatomical preoperative evaluation of distally based peroneus brevis muscle flap in reconstructive surgery of the lower limb, Journal of Plastic Reconstructive and Aesthetic Surgery, 2017, 70(11), 1563-1570.

15. Gosau, M, Schoeneich, M, Koyama, K, Jung, E.M, Fanghänel, J, Prantl, L, Ultrasound analyses, anatomical considerations, and clinical experience with the peroneus brevis muscle flap, Annals of Anatomy, 2013, 195(2), 183-188.

16. Schmidt, A.B, Giessler, G.A, The muscular and the new osteomuscular composite peroneus brevis flap: experiences from 109 cases, Plastic and Reconstructive Surgery, 2010, 126(3), 924-932.

17. Ensat, F, Hladik, M, Larcher, L, Mattiassich, G, Wechselberger, G, The distally based peroneus brevis muscle flap-clinical series and review of the literature, Microsurgery, 2014, 34(3), 203-208.

18. Erne, H, Schmauss, D, Schmauss, V, Ehrl, D, Postoperative negative pressure therapy significantly reduces flap complications in distally based peroneus brevis flaps: Experiences from 74 cases, Injury, 2016, 47(6), 1288-1292.

http://edergi.cbu.edu.tr/ojs/index.php/cbusbed isimli yazarın CBU-SBED başlıklı eseri bu Creative Commons Alıntı-Gayriticari4.0 Uluslararası Lisansı ile lisanslanmıştır. 